\title{
Research on the Influence of WeChat Public Platform on Consumers' Willingness to Buy
}

\author{
Gao Lingling, Wang Yue \\ Yunnan Open University, Yunnan Vocational \& Technical College of National Defense Industry, \\ Kunming Yunnan, China, 65000
}

Keywords: WeChat; Mobile Internet; Purchase Intention

Abstract: With the constant improvement of the mobile Internet, mobile Internet properties of all kinds of social communication software ushered in the golden period of development, of which the most WeChat development speed, according to the latest data on network platform, the current domestic WeChat has nearly 700 million active users. So users became WeChat have each enterprise the important resources in the Internet market. This article to WeChat public platform and WeChat user as the research object, explores the various factors influencing consumers' purchase intention, results show that the popularity, practicality, information quality, and release information about the special price to have a positive influence on consumer purchase intention, One of the biggest impact was on sale information, followed by usability, information quality and popularity. On this basis, this paper to enterprise WeChat marketing put forward some reasonable suggestions.

\section{Introduction}

Since the advent of the Internet, it has continued to spread and develop, and has rapidly penetrated into all walks of life and all aspects of our lives. The number of people who understand and understand the use of the Internet has been rising, and the Internet is changing the lifestyle and mode of thinking of more and more people. In addition, the continuous popularization of smart phone devices in recent years, the reduction of domestic mobile Internet traffic tariffs, the increase in Internet speed and other factors have provided a powerful driving force for the continued development of the Internet, creating favorable conditions for the arrival and development of the mobile Internet era. Under the premise of the premise, various social communication software with mobile Internet properties emerged and ushered in the prime time of rapid growth. Through comparison, it is found that the development momentum of WeChat is the fastest and the development speed is the most amazing. According to the data released on the network platform, the domestic WeChat users have exceeded 500 million mark ${ }^{[1]}$. WeChat has attracted a large number of enthusiastic users in China due to its convenience, low cost and low cost. This includes not only young students, but also middle-aged and even some elderly people. Therefore, the vast user base owned by WeChat has become an important resource for enterprises to seize the Internet market. How do small and medium-sized enterprises use the WeChat public platform for marketing, publicize and enhance their own image, attract and cultivate more consumer groups to become the main problem. To solve this problem, the first prerequisite is to understand whether the WeChat 
public platform's willingness to purchase for consumers is Influential, which content and methods in the WeChat public platform can influence consumers' willingness to purchase.

Therefore, this paper takes WeChat public platform and WeChat users as research objects, and investigates whether WeChat public platform can influence consumers' willingness to purchase through empirical research, and provides some reasonable suggestions for enterprises to better use WeChat public platform for publicity and marketing.

\section{Research Design}

\subsection{Variable measurement}

The variables studied in this paper are divided into predictive variables and outcome variables. There are four predictive variables, namely: the popularity of WeChat public platform, practicality, and special information of WeChat public platform and information quality. The resulting variable is the consumer's willingness to purchase. For the measurement of the relevant items in the questionnaire, this paper uses Likert's five-point scale to measure the consumer's willingness to purchase products or services on the WeChat public platform by 5 points. Disagree, "disagree", "general", "agree", "completely agree", the corresponding score also corresponds to 5, and the measurement content of the questionnaire is compiled by in-depth interviews.

\subsection{Sample and data collection}

The questionnaires in this paper are mainly conducted by means of network research, and mobile Internet users using smart phones are distributed to target groups, and 210 questionnaires are distributed. Among the 210 questionnaires distributed, 10 respondents indicated that they have never paid attention to the WeChat public account. These 10 questionnaires are not involved in the data analysis of other problem options. Therefore, the number of valid questionnaires is 200, and the questionnaire validity rate is $95 \%$. . This data also shows that $95 \%$ of the respondents have paid attention to the WeChat public account, which shows that the overall attention of the WeChat public platform is still very high. A total of 200 valid questionnaires were collected, which indicated that 168 respondents with WeChat frequency were higher than other social software, accounting for $84 \%$ of the total questionnaires. This shows that WeChat has a high penetration rate among mobile Internet users. The method of questionnaire distribution is conducted in a random manner, which meets the requirements of statistical analysis. The questionnaire data has research significance.

Among the 200 valid questionnaires collected, 107 were male respondents, accounting for $53 \%$ of the total respondents, and 93 were female respondents, accounting for $47 \%$ of the total number of respondents. From this data, we can see that this survey the male-female ratio of the subjects is basically the same, which also indicates that users who use WeChat and pay attention to the WeChat public platform have no special gender bias.

Respondents aged 21-30 account for $40 \%$ of the total number of people, which is the largest proportion of the total respondents to the WeChat public platform, followed by 31-40 year olds. Accounted for $34 \%$ of the total, then the total proportion of respondents in the age group of 21-40 years old is more than $70 \%$, which means that companies should use this WeChat public platform to market this age group focus on the object.

Among the respondents, the undergraduate population accounted for the largest proportion. Nearly half of the respondents were undergraduates who had paid attention to the WeChat public platform, and the second largest group of respondents with college education, the number of 62 people. The ratio reached $31 \%$, accounting for the third of the 21 students with a master's degree or above, accounting for $14 \%$, the total proportion of these three is more than $90 \%$, which shows that 
the higher education population is more We love to use WeChat and pay attention to the WeChat public platform. Enterprises should pay attention to the preferences of such people when using the WeChat public platform for marketing.

The smallest proportion of people with a monthly consumption level of less than 800 Yuan, only 7 people with a monthly consumption level below 800 Yuan, only 3\% of the total respondents, then more than nine in the interviewed population The monthly consumption level of Chengdu is more than 800 Yuan, and this group of people often use WeChat and pay attention to the WeChat public platform. The monthly consumption level is 1501-2500 Yuan, which means that the people use WeChat and pay attention to it. The WeChat public platform has a high level of consumer consumption and strong spending power. It should be profitable for companies to market their products and services on the WeChat public platform.

Based on the characteristics of the above-mentioned interviewees, this paper summarizes the balance between male and female in the group that often uses WeChat and pays attention to the WeChat public platform. The age group is biased towards the middle-aged and young people. It is generally highly educated, has a high level of consumption, and is easy to accept new things. Knowing how to enjoy life in the era of mobile Internet is not easy to exclude the marketing method of WeChat public platform. This also shows that the loyal users of WeChat are indeed an important basis for the marketing of WeChat public platform. Enterprises should conduct targeted marketing according to the characteristics of consumers when conducting the marketing of WeChat public platform.

\section{Data analysis}

\subsection{Reliability analysis}

The test method of the Krumbach coefficient mainly tests the reliability of the questionnaire by discussing the inherent consistency of the problem. Usually, when the Cronbach's $\alpha$ value is greater than 0.7 , it indicates that the questionnaire has good reliability and can be used for subsequent data analysis. The results of the above table reliability test show that the Cronbach's $\alpha$ value of the popularity is 0.911 , the practical Cronbach's $\alpha$ value is 0.857 , the Cronbach's $\alpha$ value of the information quality is 0.873 , and the Cronbach's $\alpha$ value of the special information is 0.874 , both of which are greater than 0.7 . The Cronbach's $\alpha$ value of the four factors of marketing is 0.916 , which is also greater than 0.7 . Therefore, we say that the reliability of the sample is tested by internal consistency and the questionnaire has good reliability.

\subsection{Validity analysis}

The KMO value is 0.838 , which satisfies the requirement of more than 0.7 . The significance probability is 0.000 and less than 0.001 , indicating that the sample data has better factor analysis conditions.

Therefore, we conduct principal component analysis on the scale data obtained in the questionnaire, and test the validity of the questionnaire by verifying the factor load factor values of each item affecting the four variables of the WeChat public platform marketing.

The factor load factor values of each item that affects consumers' willingness to purchase are greater than 0.5 , and the factor load factor values of these items in other variables are all less than 0.5 , indicating that each item in the questionnaire is consistent with the original Dimensional design, no need to delete any items. Therefore, each item of the questionnaire has good convergence validity and discriminant validity, and corresponds to these four variables. Therefore, the scale has high validity. 


\subsection{Hypothesis testing and results analysis}

We incorporate the consumer's willingness to purchase into the dependent variable, and incorporate the popularity, practicality, information quality and special price information of the WeChat public platform into the independent variables for regression analysis.

The significance probability is 0.00 , less than 0.01 , which indicates that the popularity and practicability of the WeChat public platform, the quality of the published information and the special information and the consumer's willingness to purchase have a significant linear relationship, with a good return effect.

The variance expansion factor values of the four independent variables are all less than 10, indicating that there is no multi-collinearity problem between the popularity, practicality, information quality and special information of the WeChat public platform. The normalization coefficient values of these four variables are $0.26,0.30,0.28$ and 0.32 , respectively; indicating that the most important influence and contribution to consumers' purchase intention is special information, followed by practicality. The third place is the information published by WeChat public platform. Quality, the least affected is the popularity of the WeChat public platform. According to the four dimensions that influence the marketing of WeChat public platform, the standard regression equation of WeChat public platform affecting consumers' willingness is: consumer willing $=0.26 \times$ popularity $+0.30 \times$ practicality $+0.28 \times$ information quality $+0.32 \times$ special information +0.91 . We can also conclude that the four variables affected by the WeChat public platform are positively correlated with the consumer's willingness to purchase, which also validates the null hypotheses.

\section{Research conclusions and marketing recommendations}

\subsection{Research conclusions}

According to the data analysis results of this paper, the popularity, practicability, information quality and release of special information of WeChat public platform all have a significant positive impact on consumers' purchasing intentions, and the impact of the release of special information on consumers' willingness to purchase. Maximum. In the early stage of the survey, the basic data was obtained through interviews, and the research hypotheses were put forward. Finally, further data were obtained by means of online questionnaire survey, and the hypothesis was verified by SPSS software. The above conclusions.

\subsection{Marketing advice}

\subsubsection{Pay attention to the attraction of special information}

We have obtained the special information on the WeChat public platform through the above data results, which has the greatest impact on consumers' purchase intention. Therefore, the first article of this marketing proposal suggests that enterprises should pay attention to the attractiveness brought by the release of special news. And this kind of marketing method is usually the simplest, the fastest, the most effective, and there are many ways to learn from the promotion. For example, enterprises can provide low-cost activities for consumers who pay attention to the WeChat public account on their official WeChat platform, or issue product coupons, and can also do limited-time snap-up activities. Enterprises use their own public WeChat platform to publish special information. The most intuitive results are generally reflected in the surge in the number of followers, such as the one-Yuan snap-up activity. The special information is reliable and reliable, and the discount is large 
enough to attract people. The attention is paid to, and brings a lot of network traffic and consumer groups. And in regular special promotions, companies can continue to accumulate new fans, cultivate loyal users, and lay a more solid foundation for the company's future WeChat public marketing.

\subsubsection{Improve the functionality of public service numbers}

The functions of the enterprise's WeChat public service number are often tailored to the service defects in the real life of traditional enterprises. The time and economic cost of using or purchasing certain services in real life are high. The function of the WeChat public platform can just compensate for this part of the loss of consumers, and can bring good customer experience to consumers. At this time, consumers will easily feel good or even rely on the WeChat public service number. Moreover, the function box provided in the WeChat public service number is clear and clear, easy to use, and has a good platform for interacting with fans. This kind of user-friendly function can retain loyal users and encourage old users to continuously develop their own side. People become new users and increase their visibility. As long as enterprises know how to use the WeChat public platform to meet the actual needs of customers, they can seize the opportunities in the fierce market competition, attract fans that enter and pay attention to the WeChat public platform, and have a huge consumer market, which directly affects the future economic benefits of the company.

\subsubsection{Actively control the quality of information on the WeChat public platform}

Most consumers who use WeChat and are concerned about the WeChat public account are consulted or understand that the information published by the WeChat public account is usually carried out using their own piecemeal time. Fragmented time means that the time period is very short. To attract the attention of consumers in this short period of time, to meet their needs, and even to encourage consumers to forward their propaganda, it is necessary to control the quality of the information sent. The truthfulness and reliability of information is the foundation. Humorous humor or touching is the means. The ultimate goal is to resonate with consumers, meet the emotional needs and material needs of consumers, and establish a good reputation for corporate brands among consumers. Word-of-mouth marketing is definitely a key point for companies to use WeChat public platform for marketing.

\section{References}

[1] China Internet Information Center. China Mobile Internet Development Status Survey Report Http://www.cnnic.net.cn/hlwfzyj/hlwfzzx/qwfb/201203/t20120329_31120.htm,2012-3-29

[2] China Internet Information Center. China SME Network Marketing Survey Report Http://www.cnnic.net.cn/hlwfzyj/hlwfzzx/qwfb/201110/t20111031_31128.htm, 2011-10-31

[3] Zhu Haibo. Analysis of Mobile Internet E-commerce Development Based on Location Service[J].Logistics Science and Technology,2008(08):29-31

[4] Zhao Huiling. Exploration of the status quo and development direction of mobile internet[J].Mobile Communications, 2009(1):13-18

[5] Deng Qinglin. The Status Quo and Development of China Mobile Internet[J]. China Data Analysis.2004(04):23-25

[6] Fu Ying. The impact of corporate micro-marketing on consumers' willingness to purchase [D].2013.01

[7] Zhou Xiuting, Zhang Shengzhan, Zhang Jianhua. Model and Strategy of Mobile Internet Marketing[J]. Journal of Changchun University of Science and Technology, 2012(09): 87-88

[8] Zhang Yan. Instant Marketing Model and Strategy Realization from the Perspective of Communication ScienceTaking WeChat Marketing as an Example [J], China Publishing House 2003 (08): 47-48

[9] Fombrun C.J.Reputation:realizing value from the corporate image [M]:Harvard Business Press. 1996

[10] Keller K.L, Aaker D.A. The impact of corporate marketing on a company brand extensions [J].corporate 
reputation review 1998,1(4):356-378

[11] Hampton-sosaw. The development of initial trust in an online company by new customer [J].information and management 2004,41(3):377-397

[12] Gefen D, karahanna E, stranb D.W Inexperience and experience with online store, The importance of TAM [J].Enginerering management.2003.50(3):307-321

[13] zeithaml valarie A.consumer perception of price,Quality, and value:A means end model and synthesis of Evidence[J].journal of Marketing.1988.52(3):2-22

[14] Grewal D, Monroe K.B, dodds.W.B.Effect of price, Brand and store information on buyer product evaluation[J].Journal of Marketing Reasearch 1991,28(3):307-319 